\title{
Lorena Soler \\ Los oficios del sociólogo en Paraguay (1950-1980).
}

FLACSO, CPES, Asunción, Paraguay, 2018

\section{Paola Adriana Bayle ${ }^{1}$}

El libro Los oficios del sociólogo en Paraguay (1950-1980) de Lorena Soler invita a reconstruir la mirada sobre la trayectoria de la sociología y de los agentes e instituciones que lograron acumular prestigio académico en este campo disciplinar en un país en el que, en relación a otros países del Cono Sur — especialmente Chile, Argentina y Brasil一, se configuró de manera periférica a estos. Dicho esto, la autora sostiene que la sociología paraguaya no estuvo aislada ni desconectada de las principales instituciones regionales e internacionales promotoras de la agenda sociológica (ni de sus agentes).

El texto focaliza en treinta años de configuración del quehacer sociológico en un contexto signado por el régimen de Alfredo Stroessner y por el proceso de modernización conservadora experimentado durante el mismo. Es, precisamente, este contexto histórico, su particularidad frente a otras configuraciones en la región, que explica, de la mano de otros procesos regionales e internacionales, el desarrollo de la sociología paraguaya entre 1950 y 1980. Si bien este recorte culmina en 1980, el trabajo se extiende, en el último capítulo, a procesos posteriores, arrojando pistas a indagar sobre el oficio del sociólogo post-stronismo.

El trabajo adopta la perspectiva de la sociología histórica para analizar el desarrollo de la sociología en Paraguay bajo un orden

Licenciada en Sociología y Doctora en Ciencias Sociales por la Universidad Nacional de Cuyo, Mendoza, Argentina. INCIHUSA, CONICET / Universidad Nacional de Cuyo, Mendoza, Argentina. Contacto: paolabayle@gmail.com 
autoritario, centrándose en el devenir de un organismo clave en el proceso de institucionalización de esta, el Centro Paraguayo de Estudios Sociológico (CPES), en la trayectoria de intelectuales estrechamente vinculados/as a este centro, y en la Revista Paraguaya de Sociología (RPS), un espacio de difusión del centro que logró posicionarse de manera privilegiada. El recorrido propuesto por Soler para reconstruir la agenda sociológica (Skocpol, 1994) en Paraguay, en esos años, se nutre de un importante acervo bibliográfico y documental, de entrevistas a agentes claves de la sociología paraguaya y de la región, y del análisis de revistas culturales, políticas, de ciencias sociales, entre otras.

El libro está estructurado en seis capítulos que no siguen, en todos los casos, estrictamente una secuencia cronológica, sino que están ordenados en función de ejes temáticos. En el capítulo primero, Soler analiza la construcción del campo intelectual y cultural paraguayo, adoptando una mirada de larga duración. Así, esta perspectiva le permite identificar las dificultades en torno a la conformación de un campo intelectual regido por sus propias reglas. La autora reconstruye la conformación del régimen político paraguayo post proceso independentista, identificando las huellas dejadas por la etapa colonial, la presencia y luego expulsión de la Compañía de Jesús y las singularidades en las distintas etapas de la construcción de la nación paraguaya. Analiza la conformación de partidos políticos modernos, de instituciones educativas, de espacios para el ejercicio artístico-cultural y de una élite intelectual generada a la par de instituciones claves. En este contexto, Soler destaca al denominado novecentismo paraguayo por su papel en la construcción de la primera corriente literaria e historiográfica del país y en la difusión de los primeros trabajos sociológicos y etnográficos en tono ensayístico.

En estricta relación con el proceso de institucionalización de la sociología, Soler identifica el primer curso de sociología dictado a principios del siglo XX en la Universidad Nacional de Asunción (UNA) por Cecilio Báez, quien difundió, en clave positivista, la potencialidad de esta disciplina en cuanto herramienta para la 
concreción del progreso en un contexto de posguerra de la Triple Alianza. En este sentido, la forma institucional de introducción de la sociología en Paraguay (bajo el formato de cátedras, cursos) y sus preocupaciones, reconoce una tendencia regional.

Entre los años veinte y cuarenta del siglo pasado, Paraguay experimentó importantes contradicciones políticas, económicas, culturales y sociales en el marco de la guerra civil y la Guerra del Chaco. Es fundamental señalar el regreso de la Compañía de Jesús al país en 1927, por su importante rol en el desarrollo de las ciencias sociales paraguayas. La sociología, en esta nueva etapa, estuvo marcada por posicionamientos antipositivistas bajo el formato de producción ensayística. Sin profundizar en lo trabajado por Soler en esta etapa, diremos que proliferaron espacios de publicación y difusión de obras culturales, literarias, historiográficas y científicas.

A partir de la segunda posguerra, y en el marco de un nuevo contexto regional regido por la hegemonía norteamericana, la historia de Paraguay está signada por el régimen stronista y la participación de Estados Unidos a través del financiamiento y del intercambio comercial. Estos factores, como los vínculos con Brasil, entre otros, produjeron un importante crecimiento económico en el país hasta los años ochenta, registrándose procesos de modernización, acompañados, sin embargo, de formas de vida conservadoras o tradicionales. La autora concluye el capítulo sosteniendo que Stroessner construyó un tipo particular de legimitidad, incorporando elementos de la democracia liberal al tiempo que ejercía la cooptación y represión contra sus opositores.

Luego de la reconstrucción histórica de las especificidades del régimen político paraguayo, y de su campo intelectual y cultural, Lorena Soler se centra en el capítulo dos en la consolidación de una forma particular de ejercicio de la sociología, tanto en la región como en Paraguay. Nos referimos al momento de "triunfo" de los autodenominados fundadores de la sociología moderna-científica en América Latina frente a otras formas de 
reflexión sociológica — señaladas por los victoriosos- como presociológicas, asistemáticas y meramente ensayísticas. En este capítulo, la autora aborda los procesos regionales e internacionales que contribuyeron a la promoción de las ciencias sociales "modernas", bajo la hegemonía de un concepto que circuló, podríamos decir, a modo de evangelio: el desarrollo.

En la segunda posguerra, la sociología alcanzó un importante desarrollo institucional en clave regional (Beigel, 2019). En esta etapa se crearon importantes organismos regionales e internacionales que difundieron y promovieron una forma particular de ciencia social: la Comisión Económica para América Latina (CEPAL), el Instituto Latinoamericano de Planificación Económica y Social (ILPES-CEPAL), la Facultad Latinoamericana de Ciencias Sociales (FLACSO) y la Oficina Regional de Educación para América Latina y el Caribe de la UNESCO (OREALC), establecidas en Santiago de Chile. A estos organismos, bajo órbita de las Naciones Unidas, hay que sumar la fuerte presencia de la Iglesia Católica en tanto financiadora y promotora también de la política de desarrollo y de las ciencias sociales, y a la Organización de los Estados Americanos (OEA). En 1967 se creó el Consejo Latinoamericano de Ciencias Sociales (CLACSO) que tuvo una estrecha vinculación con el campo sociológico paraguayo y con sus agentes más prestigiosos. Soler resalta un rasgo distintivo: la sociología en Paraguay nació en el espacio privado, por fuera del ámbito estatal; situación que se tornó estratégica frente a la censura o control del régimen stronista. No referimos al ya nombrado CPES, creado en 1964 y que logró generar una red de contactos con las principales fuentes de financiamiento de la región y acumular prestigio académico. Recién a principios de la década del setenta, se creó la carrera de sociología a la Universidad Católica Nuestra Señora la Asunción (UCA), poniendo en evidencia un vínculo entre la Iglesia Católica y las ciencias sociales que no era novedoso ni para la región, ni para Paraguay.

La autora se focaliza en agentes académicos claves del CPES, como Domingo Rivarola, quien adhirió al proyecto liderado por 
Gino Germani, entre otros, para consolidar una forma determinada de ejercer la práctica sociológica. Rivarola formó parte de élite renovadora de la sociología y lo hizo con el apoyo de instituciones financiadoras, como la Fundación Ford y CLACSO, entre otras. Este Consejo permitió visualizar en espacios regionales al CPES y le permitió construir y acumular capital social a través de varios programas académicos y los "Grupos de trabajo" en los que los paraguayos participaron. Dicho esto, la autora sostiene que, a pesar de la presencia activa de paraguayos en la red de CLACSO, su participación estuvo distanciada de los debates o producciones teóricas y, en tanto, centro periférico, desarrolló investigaciones de corte empírico. Respecto del financiamiento externo, el CPES logró canalizar fondos de fundaciones y universidades, principalmente norteamericanas, y estableció convenios con la FLACSO, lo que posibilitó la formación de paraguayos en sus posgrados y la participación de docentes de esta facultad en el CPES. Soler concluye el capítulo dando muestras de la política activa del CPES para posicionarse como el espacio legítimo — no sin disputas- para el ejercicio de la sociología preocupada por los cambios sociales.

En el "Capítulo 3", Soler analiza el campo cultural e intelectual paraguayo de los años sesenta y setenta del siglo pasado, en cuanto contexto en el que se desarrolló el proyecto de los sociólogos modernos. Este período estuvo marcado por los procesos de urbanización, radicalización de la juventud, masificación universitaria - y feminización de la matrícula - y modernización conservadora al que ya nos hemos referido. Asunción fue el escenario de nuevas expresiones literarias, artísticas y emprendimientos editoriales que promovieron al diálogo entre la literatura, la cultura y la política. Se torna vital destacar la $R e-$ vista Criterio (universitaria de izquierda) que supo canalizar las denuncias contra el financiamiento norteamericano y congregar a practicantes de sociología en pleno proceso de radicalización. En definitiva, la autora sistematiza un amplio abanico de nuevas propuestas que suscitaron la masificación de bienes culturales y la ampliación de espacios para el ejercicio de las ciencias sociales. 
En el "Capítulo 4", Lorena Soler reconstruye trayectorias académicas y militantes de la élite intelectual congregada alrededor del CPES. Este centro estuvo compuesto por graduados/as de otras disciplinas con estudios de posgrado en el exterior, principalmente en FLACSO; pues recordemos que recién en 1972 se creó la primera carrera de sociología de Paraguay en la UCA. La relación entre el equipo de la CPES y esta carrera fue estrecha, pues de ese centro se nutrió el plantel docente de la misma. Así de estrecha fue, también, la relación entre la sociología y la militancia católica (Soler, 2014), pues un grupo importante de docentes (núcleo fundante) de la carrera se iniciaron en la sociología a partir de su formación religiosa previa.

Respecto de los/as estudiantes de sociología - principalmente provenientes de colegios católicos y de familias portadoras de capital cultural-, la autora destaca que la carrera, bajo la protección de la Iglesia Católica, se convirtió en un espacio para ejercer la confrontación al régimen stronista. Recordemos que ciertos sectores de esta institución experimentaron en América Latina, a partir de los años sesenta, un proceso de radicalización política y que, en Paraguay, se reflejó, entre otras, en la conformación de las Ligas Agrarias Cristianas. Hacia finales de los años setenta, la Iglesia paraguaya adoptó una postura de acercamiento al régimen stronista frente a un estudiantado crecientemente radicalizado. En este marco, el CPES realizaba trabajos mínimos de investigación y la carrera de sociología de la UCA fue cerrada. Así, la militancia se trasladó en la defensa de los Derechos Humanos en el marco de extensión de golpes militares en la región.

En el capítulo siguiente, Soler aborda la construcción del campo sociológico frente a otros saberes y disciplinas. Retoma los años sesenta para analizar la expansión institucional en el que se desarrollaron las ciencias sociales y la profesionalización académica. La autora, para analizar el perfil del sociólogo que se impuso a partir del CPES - en disputa con otras disciplinas y saberes - se centra en la Revista Paraguaya de Sociología (RPS), editada por el centro desde 1964 hasta nuestros días. Reconstruye 
la agenda editorial a través de los artículos y autores que publicaron en ella y sostiene que se trató de un espacio de difusión del estructural funcionalismo, además del vehículo necesario para la consagración en el campo sociológico paraguayo. Paradójicamente, quienes publicaron en esta revista, en su mayoría, se habían formado en Chile en el período en que las teorías de la dependencia latinoamericana se tornaron hegemónicas y participaron del circuito regional a través de CEPAL, FLACSO y CLACSO, pero las publicaciones en la RPS no dan cuenta de un acercamiento a la sociología crítica de esos años. Los principales referentes del dependentismo no fueron citados en la RPS ni debatidos sus aportes teóricos. La autora introduce una explicación respecto de la capacidad autónoma de un centro periférico para definir su agenda de investigación frente a las fuentes de financiamiento externas. Si bien rescata los argumentos de Eduardo Devés Valdéz (2004) y de Fernanda Beigel (2010), quienes sostienen que es imposible una recepción pasiva y meramente reproductiva de los saberes que se producen en los centros hegemónicos, advierte que, para el caso paraguayo, en el contexto del stronismo y frente a la dependencia de fondos internacionales, la capacidad de ejercer una política académica autónoma se tornó muy limitada.

El lugar privilegiado de la RPS fue disputado a partir de 1973 por la revista Estudios Paraguayos, editada por la UCA en un contexto de radicalización política. La disputa incluyó la crítica por la falta de marxismo en la RPS y su adscripción al estructural funcionalismo y la teoría de la modernización.

Hacia la segunda mitad de la década de los setenta, la RPS introdujo un tema que devendría en hegemónico en las agendas de los países del Cono Sur latinoamericano: la democracia. Con este cambio de agenda, se abre el último capítulo del libro. Aquí, Soler reconstruye el papel asumido por CLACSO como promotor del nuevo debate en las ciencias sociales de la región sobre los usos y el valor de la democracia. Ante la crisis del stronismo comienzan a primar los análisis políticos y se tornan borrosos los límites entre la sociología y la ciencia política. Con la caída de Stroessner 
en 1989 y frente a nueva etapa relacionada con la direccionalidad de los fondos internacionales, el CPES perdió su monopolio como espacio legítimo para la producción sociológica. Así, hacia el siglo XXI, los/as sociólogos/as encuentran en el Estado un nuevo espacio desde donde ejercer su oficio.

A lo largo de este libro, Lorena Soler nos muestra cómo el devenir de una disciplina en un determinado campo nacional se configura históricamente y a partir del contexto social, político, cultural y económico en el que se desarrolla. Pero no solo a partir de esto, sino también, en articulación con el espacio regional e internacional en una relación de mayor o menor autonomía según el caso y el momento analizado. Como todo buen libro, provoca nuevas preguntas, al menos, en esta lectora con escasos conocimientos sobre el caso paraguayo: si durante el stronismo los/as sociólogos/as principalmente ejercían su oficio en el ámbito académico privado, ¿quiénes fueron los expertos legítimos para definir políticas de urbanización, planificación, educación, etc.?; y frente a la reapertura de la carrera de sociología, ¿cómo se definió su plan de estudios y con qué perfil profesional se graduaban sus estudiantes? Esta última y otras posibles preguntas refieren a un período no abordado por la autora en este libro, pero su lectura, además de enriquecer nuestro conocimiento sobre el devenir de la Sociología en la región, estimulas nuevas indagaciones.

\section{Referencias}

Beigel, F. (Dir.). (2010). Autonomía y dependencia académica en América Latina. Universidad e investigaciones científicas en el circuito periférico: Chile y Argentina (1950-1980). Buenos Aires: Biblos.

Beigel, F. (2019). Latin American Sociology: A Centennial Regional Tradition. En F. Beigel (Ed.) Key Texts for Latin American Sociology, (pp.1-30). Londres: Sage.

Devés Valdéz, E. (2004). La circulación de las ideas y la inserción de los cientistas económico-sociales chilenos en las redes conosureñas durante los largos 1960. Historia, 2 (37), 337-366. 
Skocpol, T.(1994). Estrategias recurrentes y nuevas agendas en sociología histórica. En W. Ansaldi (Ed.). Los fundamentos de las ciencias del hombre, (pp. 147-196). Buenos Aires: Centro Editor de América Latina.

Soler, L. (2014). “De pronto la Iglesia nos obligó a ser sociólogos”. Socialización política y stronismo. Los estudiantes de sociología de la Universidad Católica de Asunción (1971-1976). Nuevo Mundo Mundos Nuevos. Disponible en: https:/ /journals. openedition.org/nuevomundo/66560\#text 